\title{
Analysis of Hydrodynamics of Fluid Flow on Corrugated Sheets of Packing
}

\author{
Kumar Subramanian and Günter Wozny \\ Berlin Institute of Technology, Straß des 17 Juni 135 Berlin, Germany \\ Correspondence should be addressed to Günter Wozny, guenter.wozny@tu-berlin.de \\ Received 10 February 2012; Revised 7 May 2012; Accepted 16 May 2012 \\ Academic Editor: Sreepriya Vedantam
}

Copyright ( $) 2012$ K. Subramanian and G. Wozny. This is an open access article distributed under the Creative Commons Attribution License, which permits unrestricted use, distribution, and reproduction in any medium, provided the original work is properly cited.

\begin{abstract}
Modelling of the hydrodynamics behaviour of the liquid on the corrugated sheets of packing is studied using three-dimensional, volume-of-fluid (VOF) model that is incorporated in Ansys Fluent 12.0. The flow of three different liquids with different physical properties is modelled. A domain of corrugated sheets of packing resembling the real structured packing with little modifications in the elementary geometry is constructed using ICEM CFD 12.0. The quantitative comparisons of the wetting behavior from the simulations are in good agreement with experiments. Further, the study has been extended to understand the influence of the second corrugated sheet on the flow behavior. The contours from the simulations indicate the liquid hold-up in the crimp of two corrugated sheets, and these results are in good agreement with the earlier experimental studies performed using X-ray tomography in the literature. The result from the simulation shows that even for the high flow rate of around $811 \mathrm{~mL} / \mathrm{min}$ for silicon-oil (DC5), only $60 \%$ of the corrugated sheet has been wetted. Hence, the efficiency of the existing packing can be further increased by increasing the wetted area in the corrugated sheet of packing.
\end{abstract}

\section{Introduction}

The key to success in separation of liquid mixtures by distillation depends on the creation and utilization of vaporliquid contact area. The three major types of distillation equipments are trays, random packing, and structured packing. The corrugated sheet of packing, introduced in the late 1970 s, became competent by claiming higher capacity and lower sensitivity to solids while retaining the high efficiency. Hence, by 1980s, the corrugated sheets of structured packing have drawn increased attention in industry [1]. The reason for the increased efficiency with structured packing is reported as additional mass transfer due to the increase in interfacial area created by spreading liquid over the packing surface [1]. Even though the structured packing is well established, the local flow behavior inside the packing is still not well understood. Various efforts have been exerted by researchers around the world using different approaches to know about the local flow behavior that helps to design the packed column and in terms of increasing their efficiency.

Geometrical features of corrugated sheets of packing play a crucial role in flow behavior of fluid inside the packing.
Geometrical modifications of the packing are possible in three different ways: (1) varying surface of the corrugated sheet with grooved, lanced, textured, or smoothened surface, (2) changing the size of small elemental geometry like corrugation size and angle, and (3) with or without perforations.

1.1. Elementary Geometry. An elementary geometry of the corrugated sheet of packing is shown in Figure 1. The corrugation size defines the opening between adjacent corrugated layers. The ratio of $B$ to $h$ and $S$ to $h$ and the crimp angle $(\beta)$ define the geometry of flow channel and of the vapor-liquid contact zone, respectively. Packing can be classified based on the specific surface area. Crimp angle varies from $28^{\circ}$ to $45^{\circ}$, and base-to-height ratios range from $2: 1$ to $4: 1$. Most of the packing is not strictly triangle as shown below but is rounded top apex. The corrugation angle $(\alpha)$ also plays important role in deciding the capacity of the packing.

The element height is relatively low (typically 20 to $28 \mathrm{~cm}$ ), and the angle of rotation is around $90^{\circ}$. Corrugation angle of $45^{\circ}$ to the vertical enables good flow of liquid and avoids liquid accumulation. 


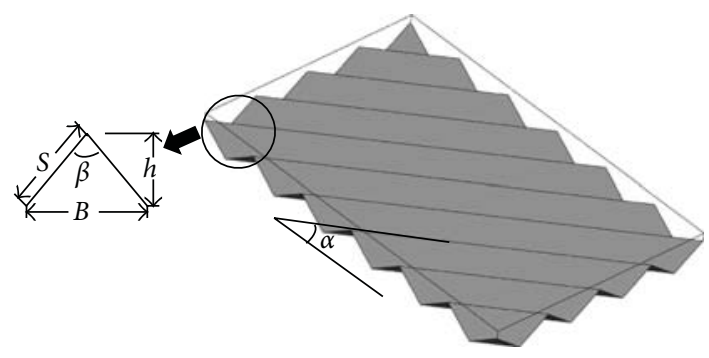

FIGURE 1: Elementary geometry details of the corrugated sheet of packing.

The effect of the opening angle on the performance of the structured packing was studied earlier [2]. Two different opening angles of $90^{\circ}$ and $20^{\circ}$ were both studied numericaland experimental-wise. It was also presented that when the opening angle was decreased from 90 to $20^{\circ}$, pressure drop of the packing could reduce by $35 \%$ and mass transfer could increase by $13 \%$ compared to Mellapak packing having the same specific surface area [2].

The results of two different packing series from Montz $\mathrm{GmbH}$ namely, B1 (embossed sheet metal, nonperforated) and BSH (expanded metal, perforated), were studied. In total, six different packings with two different corrugation angles of $45^{\circ}$ and $60^{\circ}$ and two different specific surfaces of 250 and $400 \mathrm{~m}^{2} / \mathrm{m}^{3}$ were investigated. The outcome showed that with increasing corrugation angle the pressure drop decreases, the capacity increases, and the mass transfer decreases. The holes on the surface could be the reason behind the slightly larger capacity of BSH packing in comparison with $\mathrm{B} 1$ packing. The influence of the corrugation angle on the performance of the packing was also presented [3].

1.2. Surface Features. Most of the structured packing surfaces have roughened or enhanced surfaces that assist the lateral spread of liquid, promote film turbulence, and enhance the area available for mass transfer. Measurements performed in the laboratory scale showed that mass transfer efficiency and wetter area are enhanced by textured surfaces. Texturing is of various types like grooving, lancing, shallow embossing, and deep embossing. Some different surface textures available in corrugated sheet of packing is shown in Figure 2. Figure 2(a) shows the corrugated sheet of packing without any surface textures but with perforations. Figures 2(b) and 2(c) show the three-dimensional surface textures on the packing. Various research studies have contributed exclusively to the study of the influence of surface textures on flow behavior and their further impact on mass transfer. The effect of 2-dimensional roughnesses on the flow behavior followed by gas-liquid absorption was reported [4]. The rate of absorption of $\mathrm{CO}_{2}$ into water flowing over a plate with large-scale roughness can go up to 3.5 times faster than a smooth plate. The results were also compared with theoretical correlations. Similarly, various research contributions were presented to know the influence of film flow on complex and periodic surfaces [5-7]. The surface of most of the structured packing contains perforations.
1.3. CFD Studies. The geometry representing the column of $960 \mathrm{~mm}$ height with $288 \mathrm{~mm}$ inner diameter was meshed. Four elements of packing, rotated against each other by $90^{\circ}$ with effective corrugation angle of $19^{\circ}$, were used. The model of packing of MELLAPAK 250Y made from polypropylene was employed. Simulations are carried out using CFX 10.0 to study the countercurrent two-phase flow [8]. Numerical result of the liquid flow shows the flow of liquid phase through the packing as well as the redistribution of liquid phase when liquid meets the joint of the packing elements. The flow behavior was also studied experimentally using Xray tomographic visualization technique with contrast agent racer [9].

An exclusive investigation was performed to study the flow behavior of liquid film and rivulets on inclined planes. The volume-of-fluid-like model in CFX 5.0 was utilized to study the same. The influence of surface tension was taken into account, and the simulation studies were validated with experimental work [10-13].

A direct numerical simulation to study physical and reactive absorption in gas-liquid flow on structured packing was recently published. It also showed that the liquid side mass transfer is well predicted by the Higbie theory. The numerical results were compared to approximate solution presented in the literature [14, 15]. Van Baten and Krishna [16] studied the gas and liquid mass transfer in katapak-S structures using CFD simulations, and gas phase mass transfer was in good agreement with the theoretical correlation of Viva et al. [17], whereas the liquid phase mass transfer was onefold lesser than the correlation.

In the present work, the three-dimensional volumeof-fluid (VOF) model is presented to study the flow of liquid on the corrugated sheet of packing. The surface tension of the liquid has been taken into consideration using continuum surface (CSF) model. The transient simulations are performed using the geometric reconstruction scheme for interpolation near the interface, and SIMPLEC-based solver was utilized. The comparison between the simulation and experimental studies is also presented. Further, the study was extended to study the wetting behavior for two corrugated sheets of packing.

\section{Numerical Details}

2.1. Details of the Model. The simulations are carried out with the commercial tool ANSYS Fluent 12.0, ANSYS Inc [18].

2.1.1. Volume-of-Fluid (VOF) Model. The volume-of-fluid (VOF) model, which is one of the limiting cases of EulerEuler homogenous model, is considered in this work. The VOF model considers that the gas and liquid phases are not interpenetrating. For each phase that is added, a variable is introduced. In each control volume, the volume fractions of all phases sum to unity.

The tracking of the interface(s) between the phases is accomplished by the continuity equation for the volume 


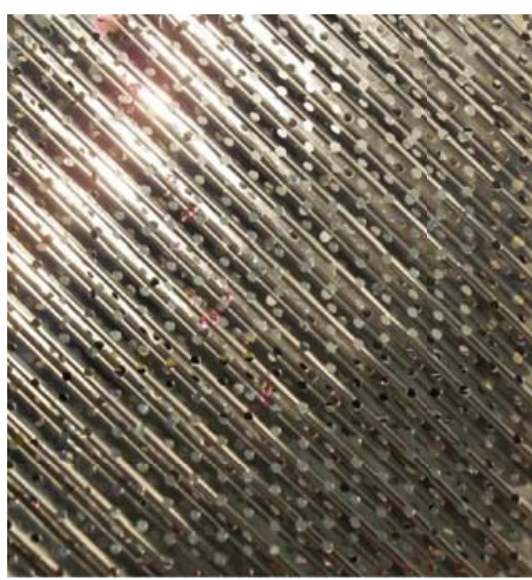

(a)

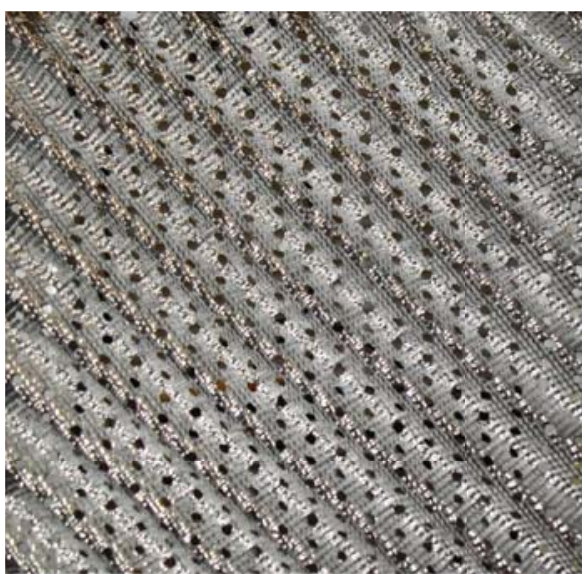

(b)

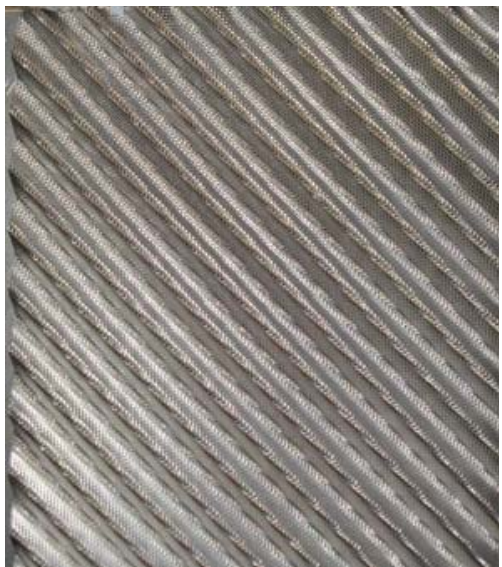

(c)

Figure 2: Different packings used in industrial applications: (a) smooth, perforated; (b) 3D grooved, perforated; (c) 3D embossed, unperforated.

TABLE 1: Details of different geometries utilized in this work.

\begin{tabular}{|c|c|c|c|c|c|}
\hline S. no. & No. of sheets & Crimp apex & Perforations & Surface textures & Crimp angle \\
\hline $\mathrm{C} 1$ & One & Sinusoidal & No & Smooth & $45^{\circ}$ \\
\hline $\mathrm{C} 2$ & One & Sinusoidal & Yes & Smooth & $45^{\circ}$ \\
\hline $\mathrm{C} 3$ & Two & Sinusoidal & No & Smooth & $45^{\circ}$ \\
\hline
\end{tabular}

fraction of one (or more) of the phases. For the $q$ th phase, this equation has the following form:

$$
\begin{gathered}
\frac{1}{\rho_{Q}}\left[\frac{\partial}{\partial t}\left(\alpha_{q} \rho_{q}\right)+\nabla \cdot\left(\alpha_{q} \rho_{q} \overrightarrow{v_{q}}\right)=S_{\alpha_{q}}\right. \\
\left.+\sum_{p=1}^{n}\left(\dot{m}_{p q}-\dot{m}_{q p}\right)\right],
\end{gathered}
$$

where $\alpha_{q}$ is the volume fraction of the $q$ th phase, $\rho$ is the density, and $S$ is the source term.

The volume fraction equation will not be solved for the primary phase; the primary-phase volume fraction will be computed based on the following constraint:

$$
\sum_{q=1}^{n} \alpha_{q}=1 .
$$

The volume fraction equation can be solved using explicit time discretization.

2.1.2. Explicit Discretization. In the explicit approach, finite difference interpolation schemes are applied to the volume fraction values that were computed at the previous time step:

$$
\begin{gathered}
\frac{\alpha_{q}^{n+1} \rho_{q}^{n+1}-\alpha_{q}^{n} \rho_{q}^{n}}{\Delta t} V+\sum_{f}\left(\rho_{q} U_{f}^{n} \alpha_{q, f}^{n}\right) \\
=\left[\sum_{p=1}^{n}\left(\dot{m}_{p q}-\dot{m}_{q p}\right)+S_{\alpha_{q}}\right] V,
\end{gathered}
$$

where $(n+1)$ is the index of the new (current) time step, $n$ is the previous time step, $\alpha_{q, f}$ is the face value of the $q$ th fraction, $V$ is the volume of the cell, and $U_{f}$ is the volume flux through the face, based on normal velocity.

\subsubsection{Interpolation near the Interface. Geometric reconstruc-} tion scheme was utilized in this work to interpolate variables near the interface between two phases.

In time-dependent VOF calculations, the time step used for the volume fraction calculation will not be the same as the time step used for the rest of the transport equations. ANSYS FLUENT will refine the time step for VOF automatically, based on the input for maximum Courant number allowed near the free surface. The Courant number (Co) is a dimensionless number that compares the time step in a calculation to the characteristic time of transit of a fluid element across a control volume:

$$
\text { Co }=\frac{\Delta t}{\Delta x_{\text {cell }} / v_{\text {fluid }}},
$$

where $\Delta x_{\text {cell }}$ is the minimum cell dimension, $v_{\text {fluid }}$ is the kinematic viscosity of the fluid, and $\Delta t$ is the time step. The time step used in the simulation is $1 * 10^{-5} \mathrm{sec}$. In the region near the fluid interface, ANSYS FLUENT divides the volume of each cell by sum of the outgoing fluxes. The resulting time represents the time it would take the fluid to empty out of the cell.

2.1.4. Surface Tension. The VOF model can also include the effects of surface tension along the interface between each pair of phases. The influence of surface tension source 


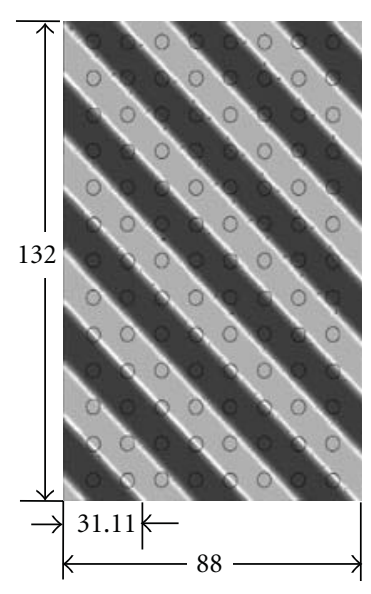

(a)

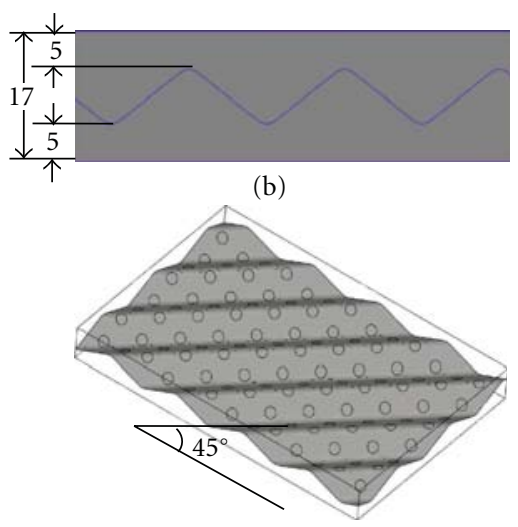

(c)

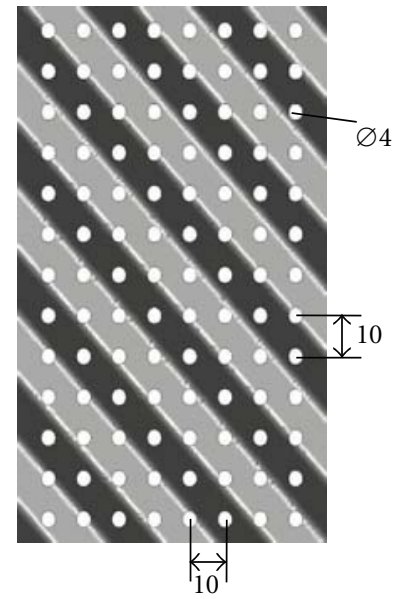

(d)

FIGURE 3: Schematic view of geometry of corrugated sheet of packing. (a) Top view: geometry without holes. (b) Side view. (c) Isometric view (d) Top view: geometry with holes. All dimensions are in $\mathrm{mm}$.

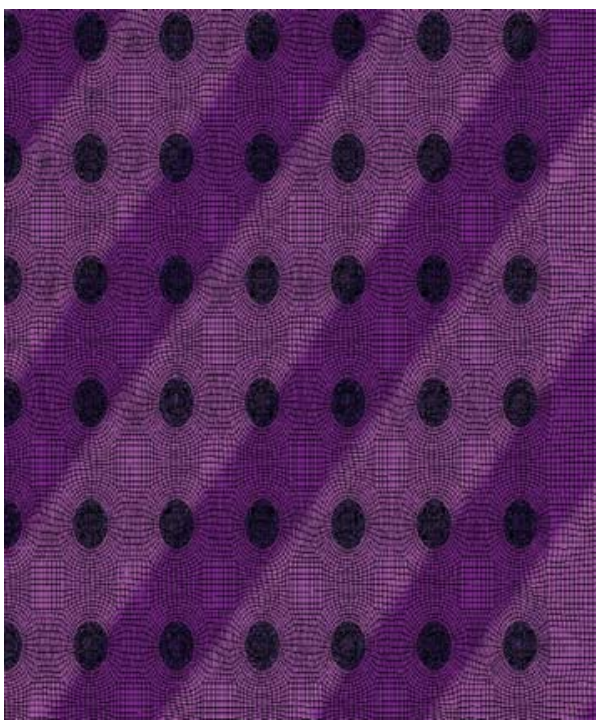

(a)

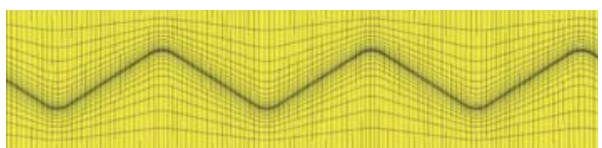

(b)

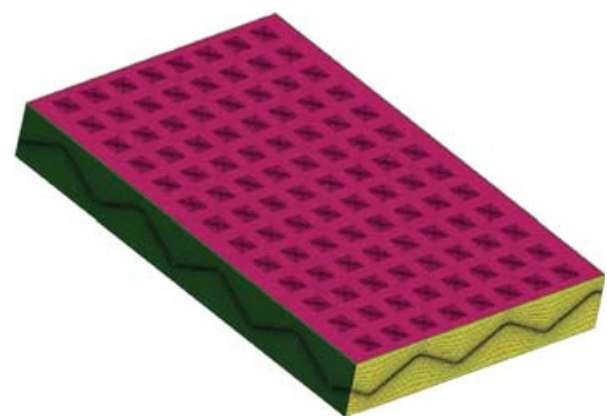

(c)

FIgUre 4: Meshes shown in detail for corrugated sheet of packing used in this work. (a) Top view. (b) Side view. (c) Isometric view. 


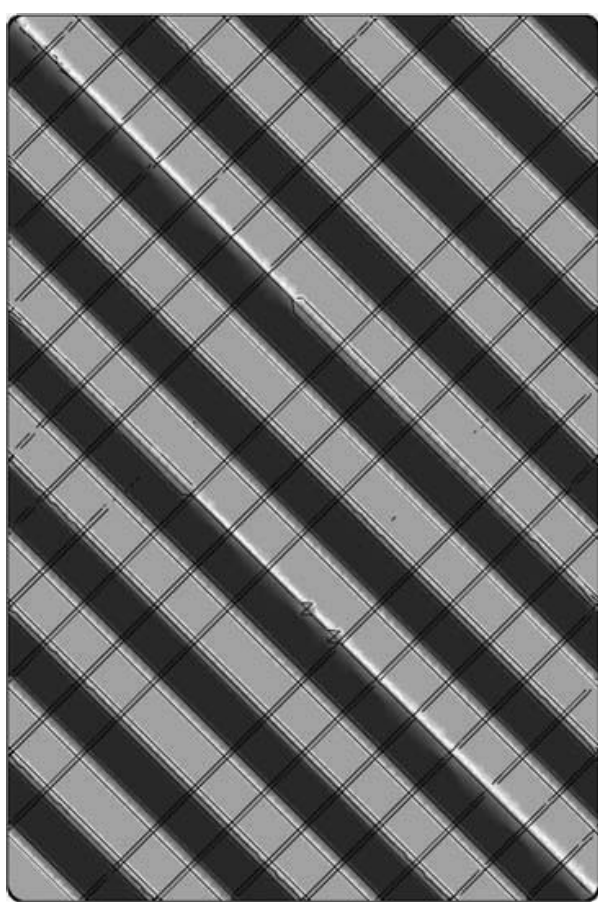

(a)

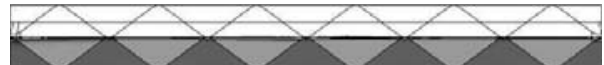

(b)

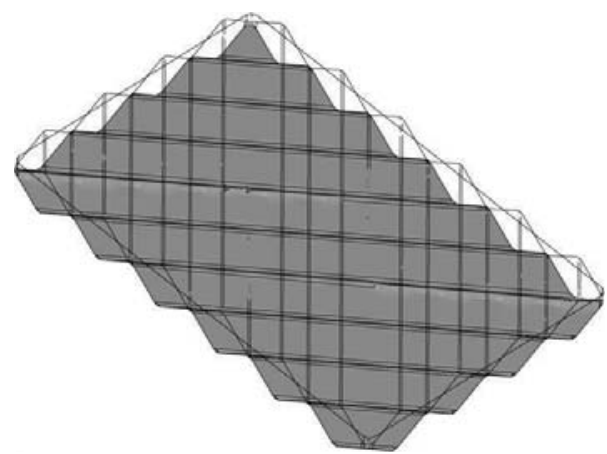

(c)

FIGURE 5: Schematic view of two corrugated sheets of packing with smooth crimp. (a) Top views (b) Side view. (c) Isometric view.

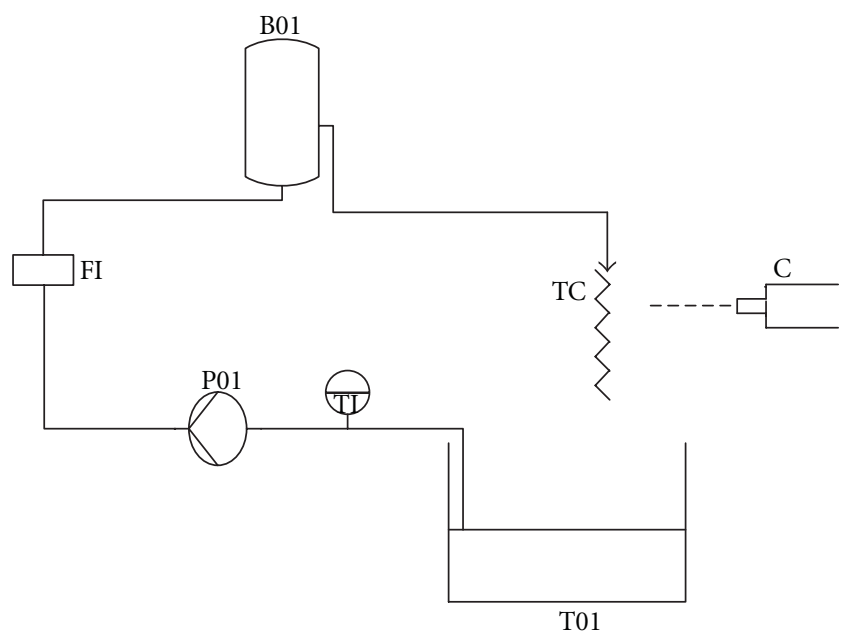

Figure 6: Experimental setup used in wetting studies. Sample picture from Water-Glycerol study. P01: pump; B01: buffer tank; TC: test cell; C: camera; FI: flow indicator; TI: thermocouple; T01: solution tank. 


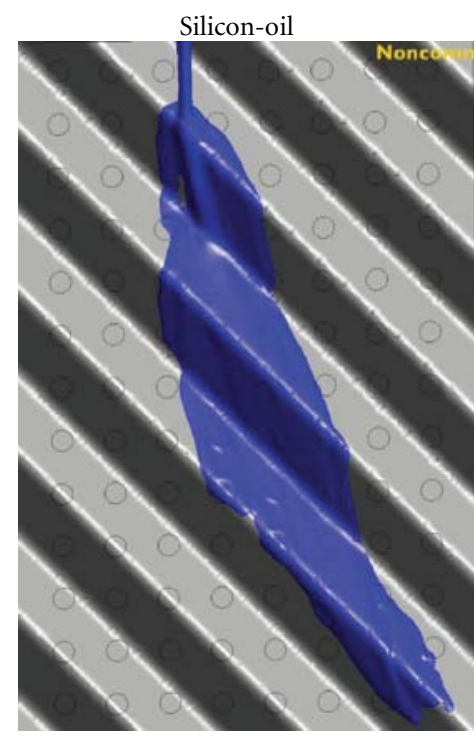

(a)

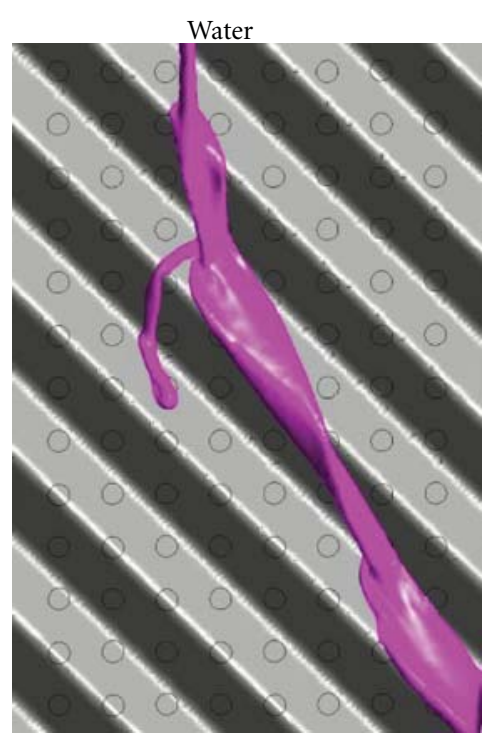

(b)

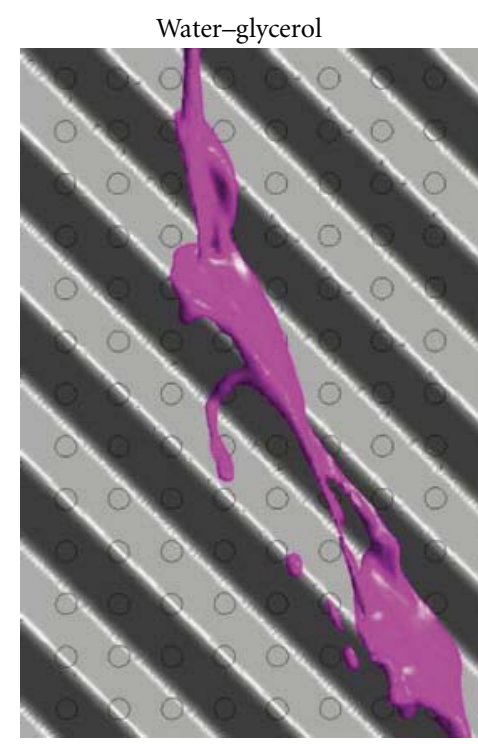

(c)

FIgURE 7: Snapshot from simulation for wetting behaviour of silicon-oil (DC5) and water and water-glycerol on corrugated sheet of packing without holes.
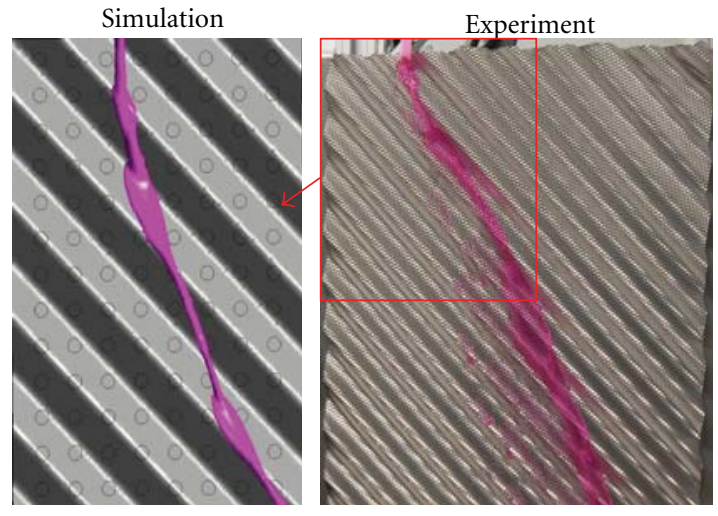

FIGURE 8: Comparison between simulation and experiment for flow of water on corrugated sheet of packing without holes. Flow rate: $386 \mathrm{~mL} / \mathrm{min}$. Rectangular box shown in red colour is the geometry considered in simulation studies.

term is taken into account by the continuum surface model (CSF) proposed by Brackbill [19]. The addition of surface tension to the VOF calculation results in a source term in the momentum equation.

All the simulations are performed under transient and laminar conditions. Detailed description of the equation and other assumptions has been already presented [20]. All the simulations are performed on IBM pSeries 690 supercomputers with SGI Altix XE 250 and in 32 parallel nodes of the HLRN (High Performance Computing Network of Northern Germany) at regional computing clusters available at Berlin.

2.2. Geometry and Dimensions. In order to study the flow behaviour in corrugated sheet of packing, three major geometries are considered in this work. Geometries are

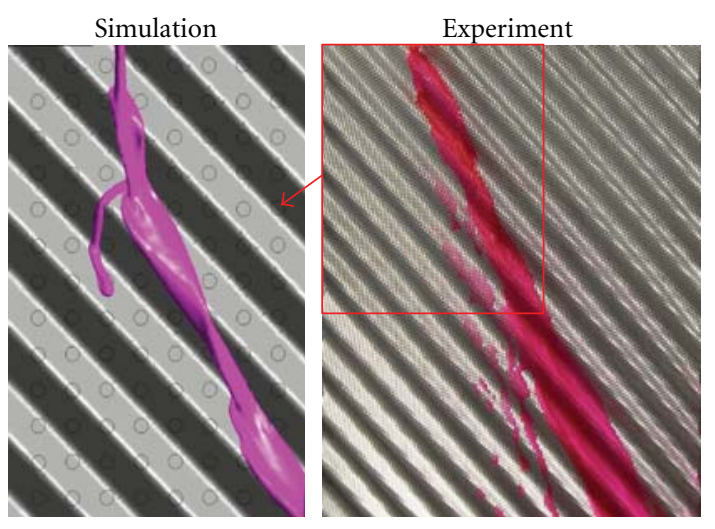

FIGURE 9: Comparison between simulation and experiment for flow of water-glycerol on corrugated sheet of packing without holes. Flow rate: $387 \mathrm{~mL} / \mathrm{min}$.
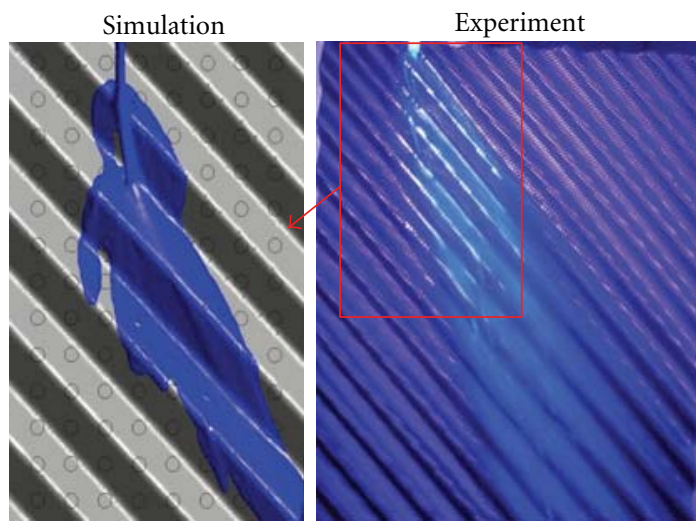

Figure 10: Comparison between simulation and experiment for flow of silicon-oil (DC5) on corrugated sheet of packing without holes. Flow rate: $241 \mathrm{~mL} / \mathrm{min}$. 


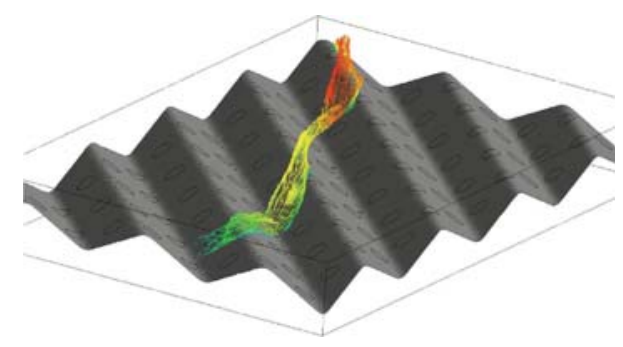

(a)

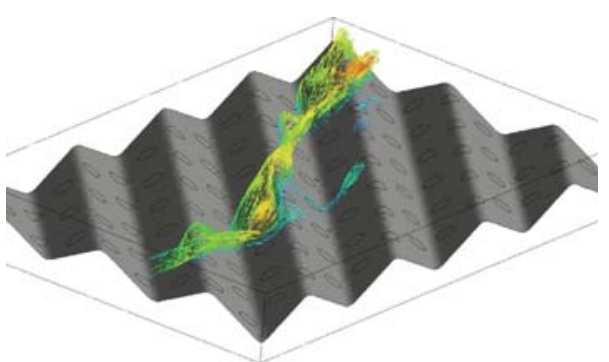

(b)

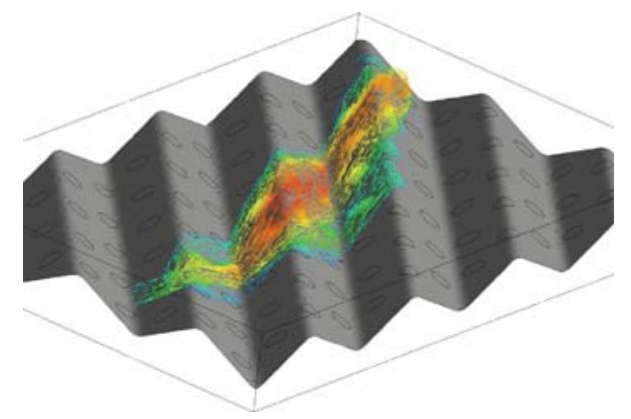

(c)

FIGURE 11: Velocity vectors for three liquids flowing through corrugated sheet of packing smooth crimp apex. (a) Water. (b) Water-glycerol. (c) Silicon-oil.

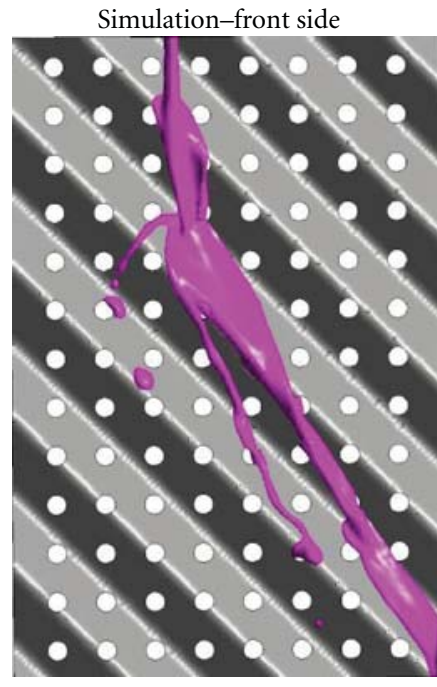

(a)

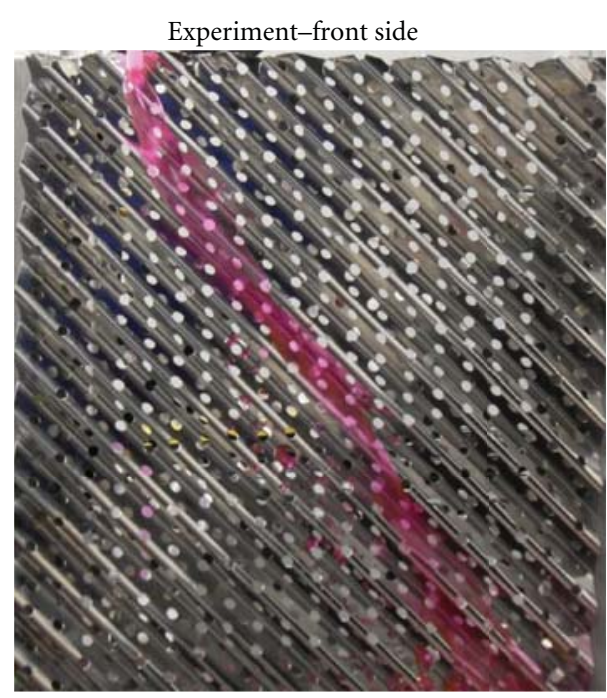

(b)
Simulation-rear side

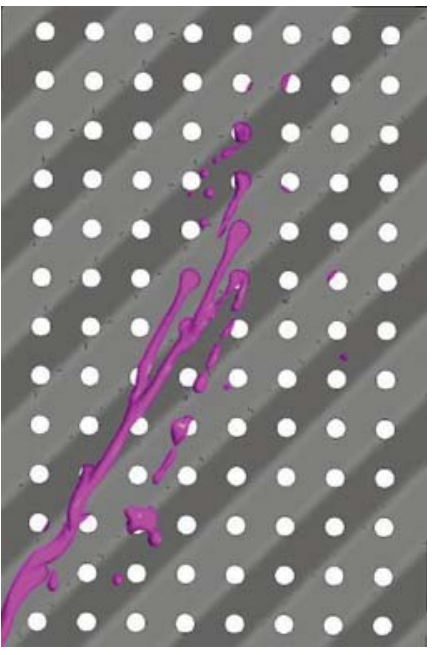

(c)

FIGURE 12: Comparison between simulation and experiment for flow of water on corrugated sheet of packing with perforations. Flow rate: $623 \mathrm{~mL} / \mathrm{min}$.

developed and meshed using ICEM CFD 12.0 [21]. List of geometries used in this work is presented in Table 1.

The detailed geometries with sinusoidal crimp are shown in Figure 3. Overall dimensions of the geometrical domain are $132 \mathrm{~mm} \times 88 \mathrm{~mm} \times 17 \mathrm{~mm}$. The corrugation angle used in all the geometries is $45^{\circ}$, and the perforation is of $4 \mathrm{~mm}$ diameter with pitch of $10 \mathrm{~mm}$ along the length and width of the geometry, which is shown in Figure 3(d). The influence of the perforations was taken into consideration by changing the boundary conditions as described in Table 2 .
Figure 4 shows the detailed meshing of the geometry shown in Figure 3, and the mesh consists of 1143600 cells. Figure 5 shows the geometry in which two corrugated sheets are arranged as in practical applications, one corrugated sheet is turned $90^{\circ}$ to the other.

2.3. Boundary Conditions. Details of the boundary conditions used in the simulations are listed in Table 2. The influence of perforations has been brought in simulation by changing the boundary conditions of holes in the geometry. 


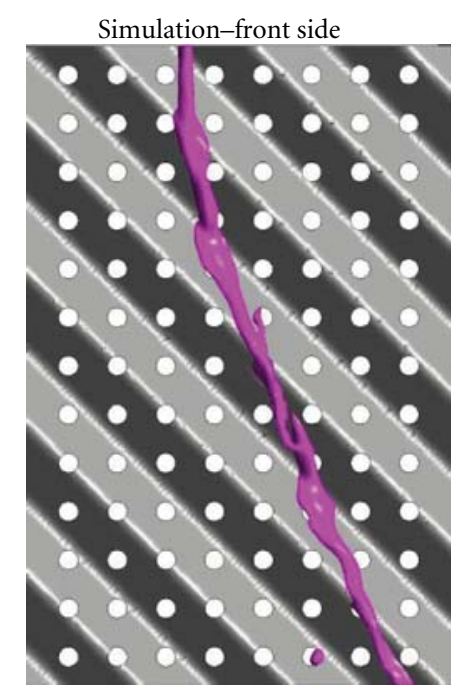

(a)

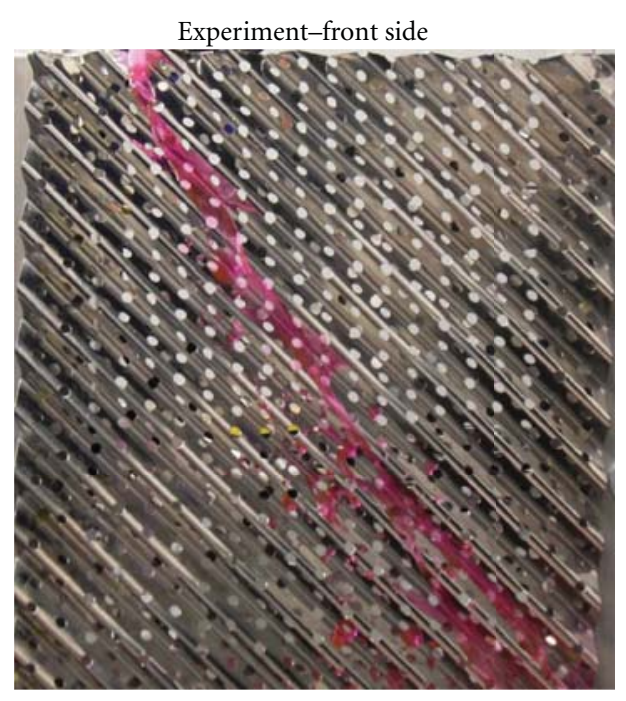

(b)

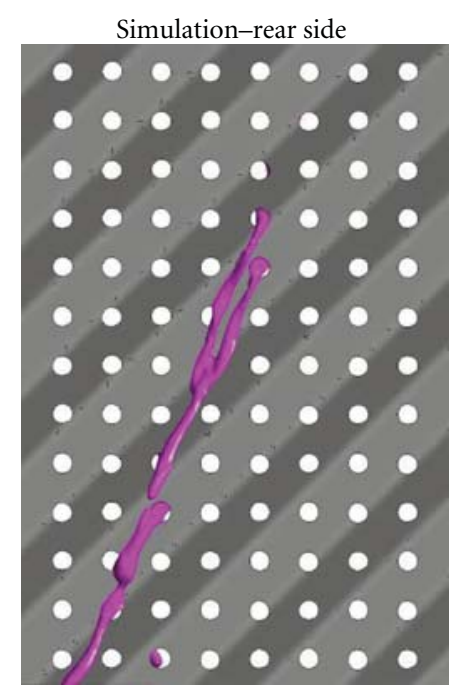

(c)

FIGURE 13: Comparison between simulation and experiment for flow of water on corrugated sheet of packing with perforations. Flow rate: $386 \mathrm{~mL} / \mathrm{min}$.

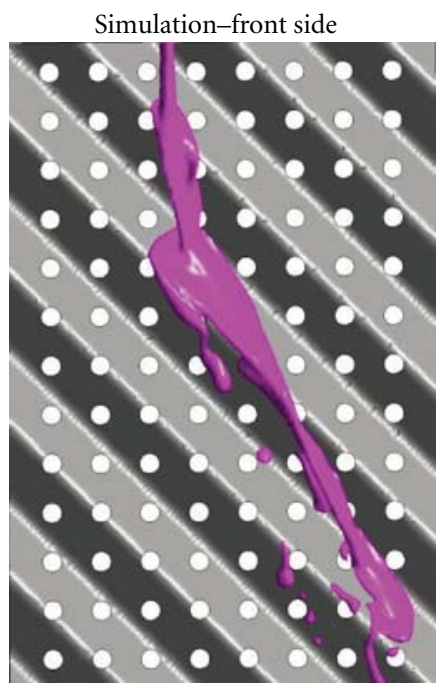

(a)

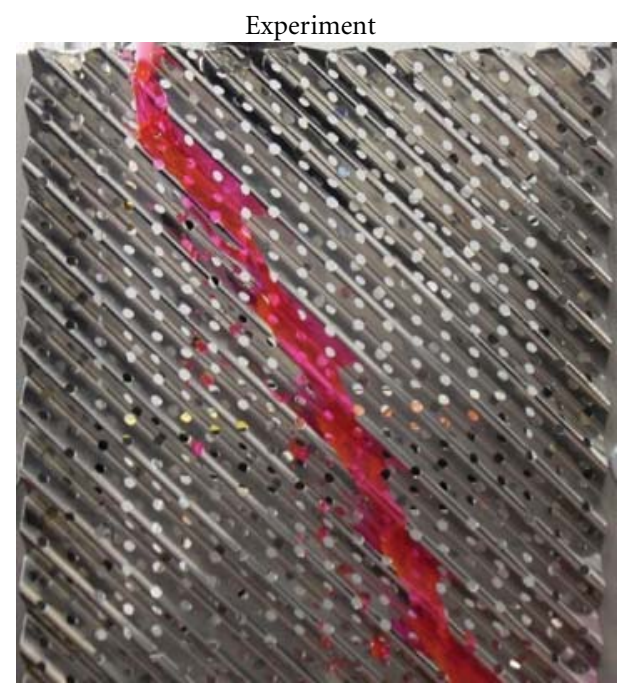

(b)

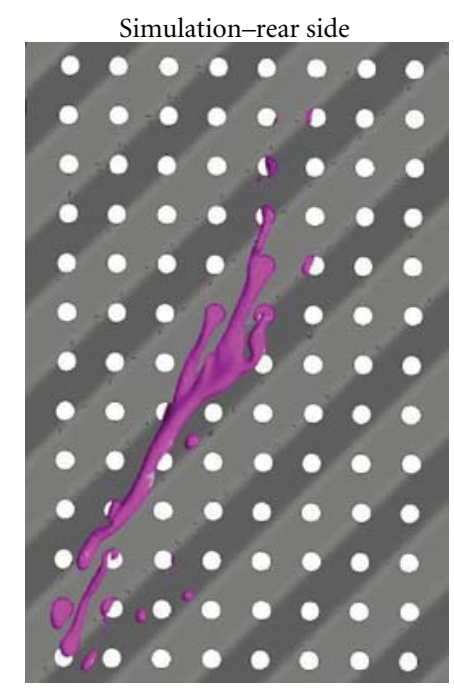

(c)

FIGURE 14: Comparison between simulation and experiment for flow of water-glycerol on corrugated sheet of packing with perforations. Flow rate: $590 \mathrm{~mL} / \mathrm{min}$.

For the simulation with perforations, boundary conditions of the perforations will be assigned as interior, otherwise it will be assigned as wall. This method helps in using the same geometry for both the simulations and helps in comparing the influence later.

As described in Section 2.1, simulations are performed on three major geometries. For geometry $\mathrm{C} 1$ and $\mathrm{C} 2$, one inlet of $4 \mathrm{~mm}$ pipe was considered just to resemble real flow distributors used in industries. Three different flow rates are studied for each testing system. The details of the flow rates and Reynolds number presented in this work are shown in Table 3 .

For simulation using geometry C3, 4 inlets each of $4 \mathrm{~mm}$ diameter were considered for study. The aim of using these
4 inlets is to study the maximum wetting possibility in the corrugated sheet of packing. Hence, very high flow rate of $811 \mathrm{~mL} / \mathrm{min}$ was studied. Two major inlet positions as described in Section 3.3 are also considered.

2.4. Testing Systems. Three different fluids with difference in viscosity and contact angle were selected for this study. The details of the liquids are listed in Table 4. Waterglycerol (45 wt $\%)$ and water have similar contact angle but Water-glycerol has higher viscosity than water. Silicon-oil (DC5) has very low contact angle but similar viscosity to that of Water-glycerol ( $45 \mathrm{wt} \%)$. To capture the wetting, Rhodamine- $\mathrm{B}$ was used as coloring pigment in water and 


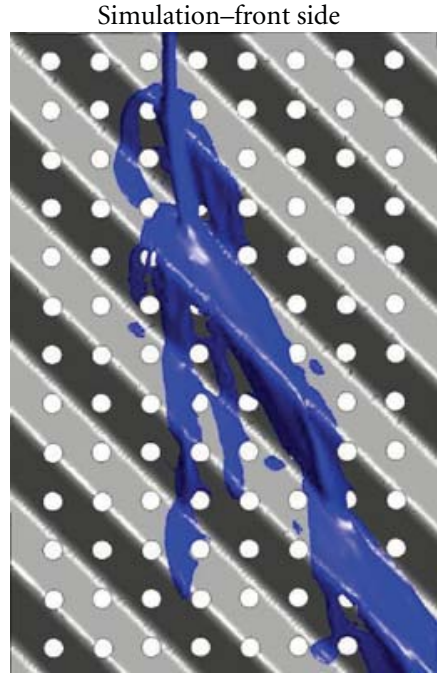

(a)

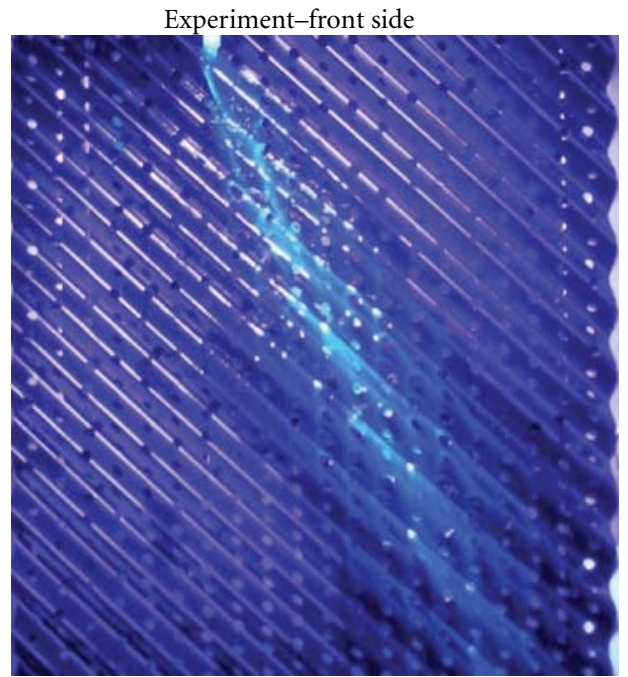

(b)
Simulation-rear side

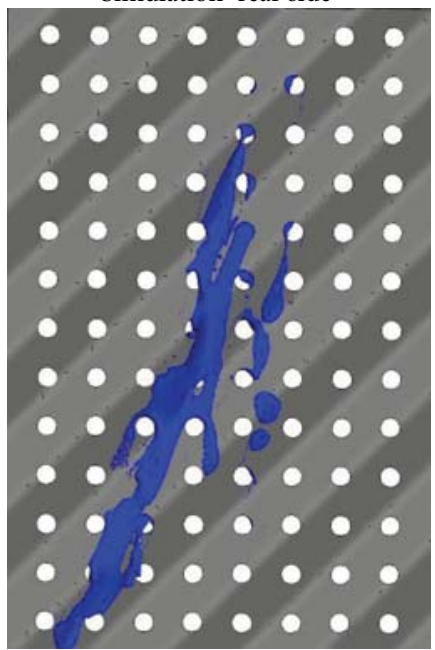

(c)

FIGURE 15: Comparison between simulation and experiment for flow of silicon-oil on corrugated sheet of packing with perforations. Flow rate: $508 \mathrm{~mL} / \mathrm{min}$.

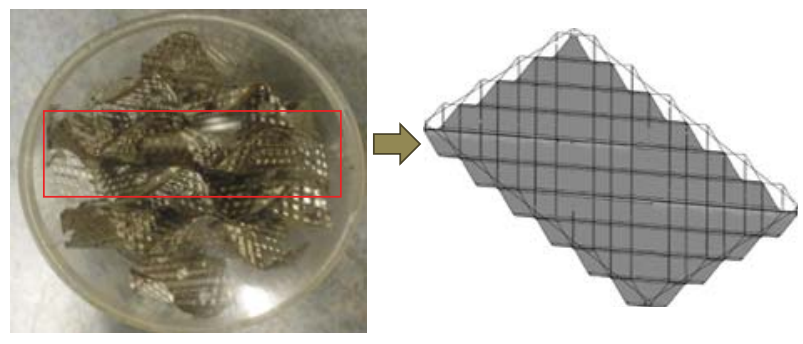

Figure 16: Comparison of domains used in simulation from real packing geometry.

TABLE 2: Boundary conditions used in the simulations.

\begin{tabular}{lcc}
\hline & $\begin{array}{c}\text { Simulation without } \\
\text { perforations }\end{array}$ & $\begin{array}{c}\text { Simulation with } \\
\text { perforations }\end{array}$ \\
\hline Inlet & Velocity inlet & Velocity inlet \\
Outlet & Pressure outlet & Pressure outlet \\
Top & Pressure outlet & Pressure outlet \\
Bottom & Pressure outlet & Pressure outlet \\
Corrugation-base & Wall (CA) & Wall (CA) \\
Corrugation-holes & Wall (CA) & Interior \\
Sides & Symmetry & Symmetry \\
\hline
\end{tabular}

water-glycerol solution. As the color of the testing system is pink, the wetting can be studied without the help of UVlight. The usage of this coloring pigment has been studied earlier [22], and this will not influence any of the physical parameters of the testing system. For silicon-oil (DC5), Coumarin was used as a coloring agent, which gives blue reflections when studied with the help of UV-light. But the corrugated sheet must be coated with black color to capture the UV light.
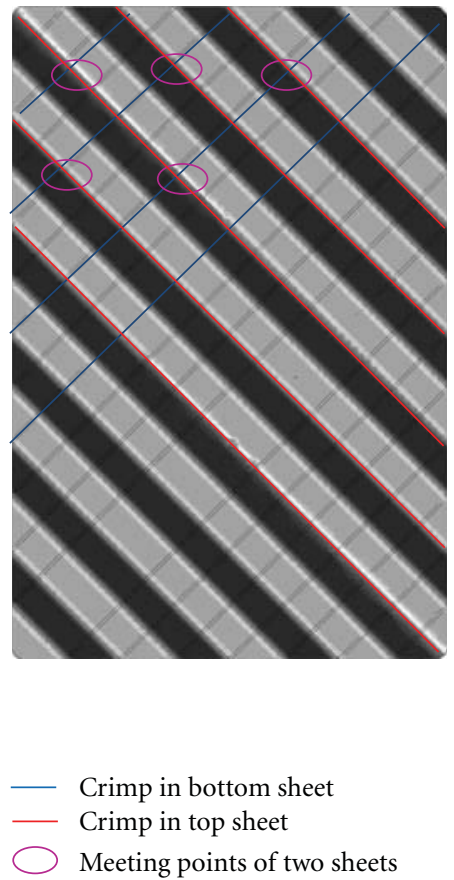

FigURE 17: Explanation of meeting points from two corrugated sheets of packing and interest of our study.
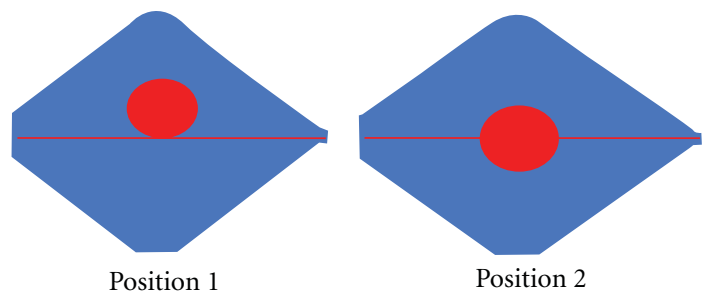

Figure 18: Two inlet positions used in the simulation. 
TABLE 3: Details of the flow rate and Reynolds number presented in this work.

\begin{tabular}{lcc}
\hline & Flow rate (mL/min.) & Re \\
\hline \multirow{2}{*}{ Water } & 386 & 2033 \\
& 623 & 3291 \\
Water-glycerol (45\%) & 386 & 486 \\
\multirow{2}{*}{ Silicon-oil (DC5) } & 590 & 743 \\
& 241 & 230 \\
& 508 & 486 \\
\hline
\end{tabular}

TABle 4: Properties of the testing system.

\begin{tabular}{lcccc}
\hline & $\begin{array}{c}\text { Viscosity } \\
\eta(\mathrm{mPa})\end{array}$ & $\begin{array}{c}\text { Density } \rho \\
\left(\mathrm{kg} / \mathrm{m}^{3}\right)\end{array}$ & $\begin{array}{c}\text { Surface tension } \\
\sigma(\mathrm{mN} / \mathrm{m})\end{array}$ & $\begin{array}{c}\text { Contact } \\
\text { angle } \theta\left(^{\circ}\right)\end{array}$ \\
\hline $\begin{array}{l}\text { Water } \\
\begin{array}{l}\text { Water-glycerol } \\
(45 \text { Wt\% })\end{array}\end{array}$ & 1 & 997 & 72.7 & 76.6 \\
$\begin{array}{l}\text { Silicon-oil } \\
(\text { DC5 })\end{array}$ & 4.6 & 1113 & 70 & 69 \\
\hline
\end{tabular}

TABLE 5: Wetted area for bottom and top of the packing in $\%$ for silicon-oil (DC5).

\begin{tabular}{lcc}
\hline & Position 1 (\%) & Position 2 (\%) \\
\hline Bottom sheet & 5.07 & 15.36 \\
Top sheet & 54.42 & 39.06 \\
\hline Total & 59.49 & 54.42 \\
\hline
\end{tabular}

2.5. Experimental Setup. The flow diagram of the experimental setup is shown in Figure 6. Test liquids were pumped using pump (P01) from the solution tank (T01) to flow through the test cell (TC). Before flowing through the test cell, it passes through the flow indicator (FI) and buffer tank (B01). Buffer tank is used in order to avoid pulsations arising from the pump. A camera (C) is placed in the stand opposite to the corrugated sheet, which enables taking pictures.

\section{Results and Discussion}

3.1. Flow on Corrugated Sheet with Smooth Crimp Surface without Holes. In this section, comparison between experiment and simulation for flow of three different liquids on corrugated sheet of packing is presented. In Figure 7, a snapshot from simulation for a qualitative comparison of wetting behavior of silicon-oil (DC5), water, and waterglycerol on corrugated sheet is presented. It can be seen that the fluid with low contact angle, that is, silicon-oil (DC5), has more wetting in comparison to water and water-glycerol (45 wt \%), which has very high contact angle. In other words, water, and water-glycerol system with high contact angle has a tendency to change its direction towards the corrugation than silicon-oil.

In Figures 8, 9, and 10, the flow and wetting behavior of water, water-glycerol, and silicon-oil (DC5) over corrugated sheet without perforations are shown in comparison with experimental studies. Geometry utilized in the simulation is similar to Figure 3. Liquid flows through circular inlets of
$4 \mathrm{~mm}$ diameter, which reflects the distributors utilizing in real-time industrial applications, which stands at $90^{\circ}$ from base. Experiments are performed on Montz B1-300 packing, which has textured surface. However, geometry used in the simulations is without microstructure on the surface. Hence, the differences are needed to be considered while comparing the simulation and experiments.

As seen in Figures 8-11, the direction of the flow of liquid changes in the direction of corrugation, which helps to utilize the packing surface effectively and hence the wetting area increases. When the liquid flows inside corrugation, the width of the liquid flow is more while it is lesser in the crimp of packing. In turn, the thickness of the liquid is more in the crimp of packing, which can be seen in Figures 8-11. This phenomenon is also in accordance with earlier experimental studies where the liquid hold-up is reported to be more around the crimp [23].

While comparing Figures 8 and 9 with Figure 10, the influence of contact angle can be noticed. The wetting of liquid with low contact angle, that is, silicon-oil (DC5), is higher than the wetting of water and water-glycerol Figures 9 and 10.

In Figure 11, closer view of the velocity vector is shown to understand the smooth flow of the liquid over the crimp of the corrugated sheet of packing. It is clear from this section that the liquid with low contact angle has very good wetting behaviour, which is also in accordance with our earlier studies with smooth inclined plate. The corrugation in the packing sheets helps the fluid to flow longer by changing the direction along the corrugation. This increases the contact time of the liquid-gas inside the packing.

3.2. Flow on Corrugated Sheet of Packing with Holes. In this section, the flows of different testing liquids on the corrugated sheet of packing with holes are shown. Figure 12Figure 15 show the wetting on corrugated sheet of packing with smooth crimp surface and with holes for water, water-glycerol and silicon-oil. Figures 12 and 13 show the hydrodynamics of flow of water at two different flow rates. Figures 14 and 15 show the flow behavior of water-glycerol, and silicon-oil (DC5).

The influence of perforations can be clearly seen while comparing Figure 8-Figure 10 with Figure 12-Figure 15. Due to perforations, both sides of the corrugated sheet are wetted. However, the wetting area on the front side of the corrugated sheet considerably reduced in comparison to the sheet without perforations.

In Figure 12-Figure 15, comparison between experiment and simulation is also shown. The flow on the front side of the sheet is shown in comparison with simulation and experiment. It is very tedious to capture the flow on the rear side of the corrugated sheet experimentally. Hence, the flow on the rear of the packing is shown from CFD simulations.

By comparing Figures 12 and 13, the change in wetting due to change in flow rate can be observed. The wetting of water at high flow is more (Figure 12) compared to at low flow rate (Figure 13). On the other hand, it should be noticed that holes are utilized more in the low flow rate. Hence, 
the wetting on the rear side of the packing is more for low flow rate. So it looks like flow rate and holes play a contradictory role while wetting.

While comparing Figures 13 and 15, it can be understood that for high viscous fluids the flow wetting behavior has no big difference.

As seen in Section 3.1, silicon-oil has shown better wetting in the corrugated sheet of packing with perforations as well (Figure 16). The wetting on the front side of the packing is less in comparison with the packing without perforations. But the wetting on the rear side is considerably high. For silicon-oil, the change in flow rate did not make a huge difference in wetting the rear side of the sheet (not shown here).

Overall, the presence of perforations plays a key role in wetting and hence increases the contact area for the liquid gas interaction. Hence, in recent times, almost all the industrial packings have perforations. Now with this study, the wetting on the rear side of the packing can also be understood, which is usually cumbersome with experiments.

3.3. Two Corrugated Sheets of Packing. The major aim of this section is to study the extent of wetting on two corrugated sheets of packing. In reality, corrugated sheets of packing are arranged in such a way that one, sheet is placed $90^{\circ}$ opposite to the other one, that is, corrugation lies in the opposite direction, helping the fluid to change its direction. Figure 16 shows the domain of the geometry used for simulation in comparison with real packing segment. As shown, only part of the packing segment is considered for simulation in order to understand the influence of the second sheet in the liquid hold-up and in the wetting pattern. The main region to be considered is the meeting points where two corrugated sheets touch each other, which are explained in Figure 17.

Simulations are performed with the inlet conditions described as follows.

(i) Inlets are $4 \mathrm{~mm}$ diameter liquid distributors as seen in Section 3.1

(ii) Four inlet distributors are considered to understand the maximum wetting possible with two corrugated sheets of packing.

(iii) Two different inlet positions are considered as shown in Figure 18. Two inlet positions are chosen in such a way that one position is inside the corrugation of bottom sheet (Position 1) and the other position is outside the corrugation of bottom sheet (Position 2). By this, the influence of the meeting point due to the second corrugated sheet on the flow of liquid can be clearly seen.

(iv) Silicon-oil with volumetric flow rate of $811 \mathrm{~mL} / \mathrm{min}$ showed the maximum wetting in our earlier studies.

Figures 19 and 20 show the isometric view of volume fraction of silicon-oil at different heights of the corrugated sheet of packing along the flow direction. It can be clearly seen that the liquid holds up near the criss-cross junction, that is, around the meeting point of the two sheets. Moreover,

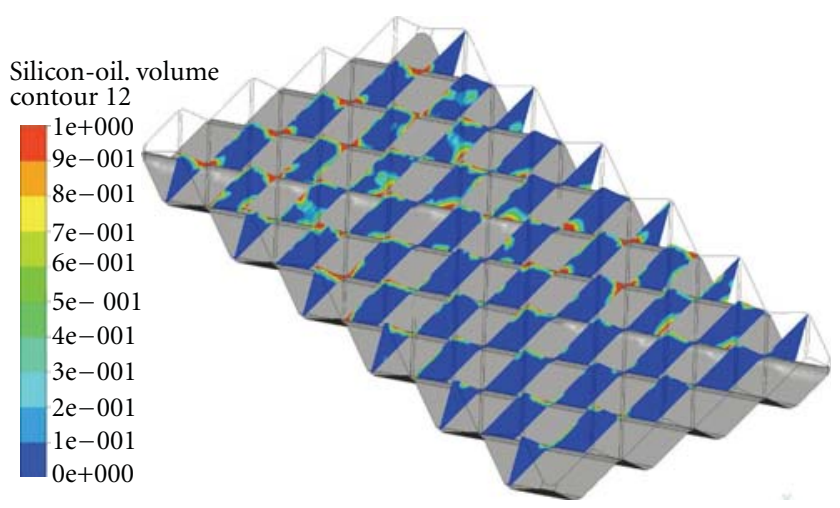

FIGURE 19: Contour of silicon-oil volume fraction at different heights of corrugated sheet of packing simulated along the flow direction for inlet position 1 . Vol. Flow rate $=811 \mathrm{~mL} / \mathrm{min}$.

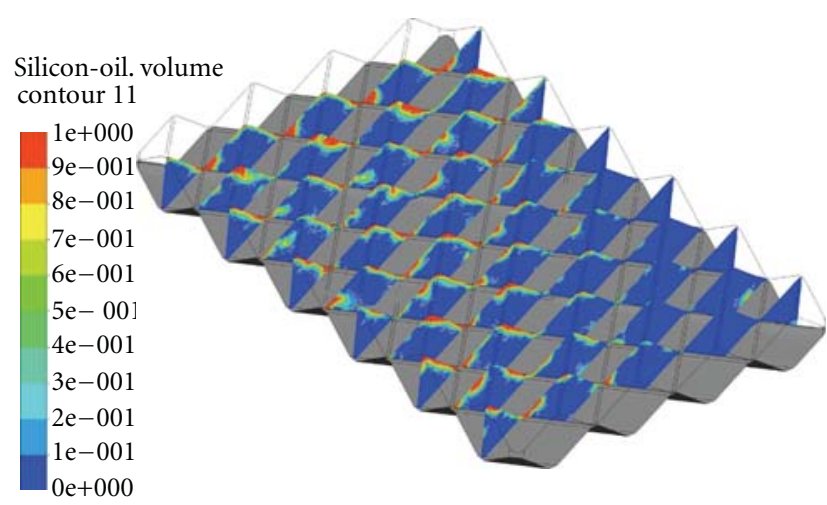

Figure 20: Contour of silicon-oil volume fraction at different heights of corrugated sheet of packing simulated in the flow direction for inlet position 2. Vol. Flow rate $=811 \mathrm{~mL} / \mathrm{min}$.

the hold-up is more near the inlet than in the outlet. This phenomenon of liquid holding up near this junction is seen in experimental study [23] performed using X-ray tomography for Mellapak 752.Y.

Figures 21 and 22 show the wetting of bottom and top sheets for simulation with two corrugated sheets of packing and for two different inlet positions mentioned earlier but for the same flow rate. It is very interesting to note that along with the liquid hold-up, small change in inlet positions makes a huge impact on wetting of the corrugated sheet. For position 1, where most of the portion of inlet lies inside the corrugation of top sheets wets only the top packing sheet and the bottom sheets remain without wetting. For position 2, where the inlet lies equally to both the corrugated sheets, wets more of the bottom sheet and considerably less of the top sheet compared to position 1 .

In Table 5 , the wetted areas of bottom and top corrugated sheets are shown. It is clear from position 1 that only $54 \%$ and $5.07 \%$ of top and bottom sheets are wetted, respectively. Moreover, in case of position 2, the wetted area is $15.36 \%$ and $39.06 \%$ for bottom and top sheets, respectively. Overall, only 55 to $60 \%$ of the packing area is utilized. 


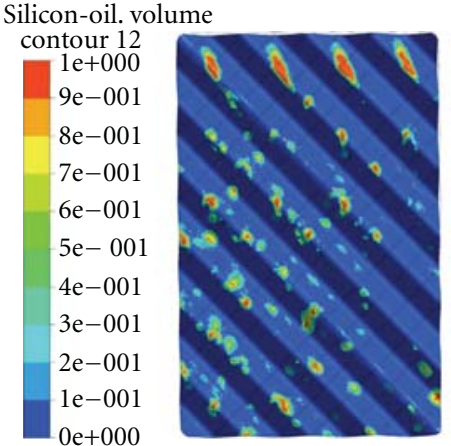

(a)

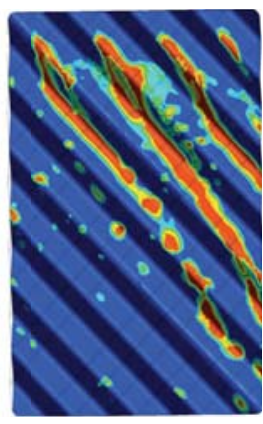

(b)
Figure 21: Wetted area on the bottom packing for two inlet positions. (a) Position 1. (b) position 2. Vol. Flow rate $=811 \mathrm{~mL} / \mathrm{min}$.

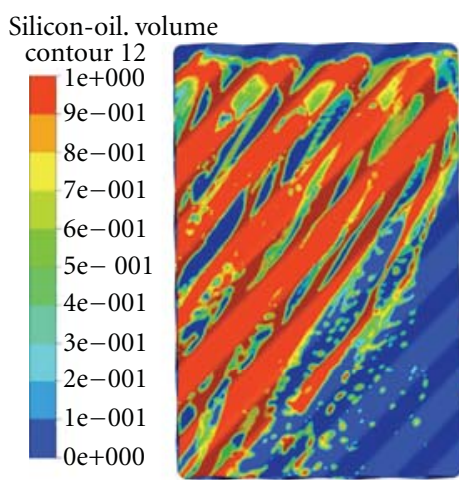

(a)

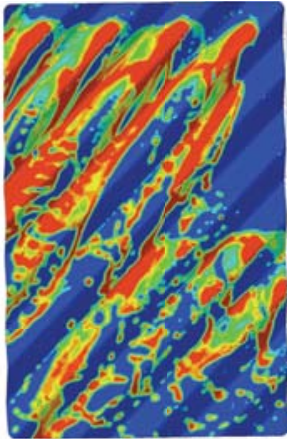

(b)
FIgURE 22: Wetted area on the top packing for two inlet positions. (a) Position 1. (b) Position 2. Vol. Flow rate $=811 \mathrm{~mL} / \mathrm{min}$.

As shown, only maximum of $60 \%$ of the packing area is utilised for wetting of testing system with low contact angle (which usually wets easily), for maximum inlet possible, that is, four inlets through four corrugations and relatively high flow rate of around $811 \mathrm{~mL} / \mathrm{min}$. It is very clear that around $40 \%$ of the area can be utilised and hence efficiency of the packing can be further improved. The influences of surface textures are not considered in the simulation, which can be considered further in simulation studies to understand the wetting behaviour better.

\section{Conclusions}

The three-dimensional VOF model is presented in this work in order to study the flow of liquid on the corrugated sheets of packing. Geometries with three different modifications in the element of the geometry have been studied. Three different testing fluids with different physical properties were considered. The simulations are performed in the $3 \mathrm{D}$ geometry resembling the corrugated sheet of packing. The simulations are compared with quantitative experimental studies. The corrugation changes the direction of the flow of fluid, and this increases the contact time of gas-liquid in the packing. As expected, the increase in flow rate also increased the wetting area. Testing mixture with low contact angle had better wetting.

The influence of perforations on wetting of the corrugated sheet was also shown. The wetting area on the front side of the sheet decreases while the liquid wets the rear side of the packing. Liquids flowing at low flow rate utilize the perforations more and wet both sides of the sheets. The increase in flow rate counter affects the presence of perforations. Due to high flow rate, perforations are not utilized completely hence the wetting on the rear side of packing was lesser compared to low flow rate.

The second corrugated sheet was introduced to simulation domain to understand the influence of criss-cross junctions where both the sheets touch each other. Liquid hold-up near the junctions of two sheets was high, as noticed in some experimental studies performed using Xray tomography [17]. It is also shown that the minor change in position of the inlet distributors considerably changes the wetting area and the flow direction of the liquid. Even for the simulation performed with the maximum number of inlets and for liquid with low contact angle, the complete area of packing was not utilized. This clearly proves that the efficiency of the existing packing can be further increased. The wetting of the corrugated sheet of packing can be further increased by textures on the surface. This theoretical work can be extended to study the wetting behavior on the corrugated sheet with microstructures on the surface of the packing. Various surface textures are possible as explained earlier in Section 1.2. The influence of the different 2D and 3D microstructures can be studied. Considering the validity of this model, dimension ( $\mathrm{nm}$ to $\mathrm{mm}$ ) of the microstructure can be optimized to achieve maximum wetting and hence high mass transfer. It is highly recommended to study the influence of microstructures using the CFD simulations, which will help to develop new surface textures to utilize the surface of packing completely. With the validated model, experiment efforts can be reduced but cannot be avoided completely. This study can also be further extended to study the transport processes in distillation and absorption.

\section{Acknowledgments}

The authors thank the management committee of Evonik Stiftung for funding this project and are grateful to HLRN Berlin for using parallel computing in clusters. They also thank Mr. Martin Kohrt for his technical assistance in experimental study and Dr. Ilja Ausner for supplying the packing sheets for experiments.

\section{References}

[1] H. Kister, Distillation Design, McGraw-Hill, 1992.

[2] S. J. Luo, W. Y. Fei, X. Y. Song, and H. Z. Li, "Effect of channel opening angle on the performance of structured packings," Chemical Engineering Journal, vol. 144, no. 2, pp. 227-234, 2008.

[3] Ž. Olujić, A. F. Seibert, and J. R. Fair, "Influence of corrugation geometry on the performance of structured packings: an experimental study," Chemical Engineering and Processing, vol. 39, no. 4, pp. 335-342, 2000. 
[4] J. T. Davies and K. V. Warner, "The effect of large-scale roughness in promoting gas absorption," Chemical Engineering Science, vol. 24, no. 2, pp. 231-240, 1969.

[5] L. Zhao and R. L. Cerro, "Experimental characterization of viscous film flows over complex surfaces," International Journal of Multiphase Flow, vol. 18, no. 4, pp. 495-516, 1992.

[6] S. Shetty and R. L. Cerro, "Flow of a thin fiom over a periodic surface," International Journal of Multiphase Flow, vol. 19, no. 6, pp. 1013-1027, 1993.

[7] S. Shetty and R. L. Cerro, "Spreading of a liquid point source over a complex surface," Industrial and Engineering Chemistry Research, vol. 37, no. 2, pp. 626-635, 1998.

[8] B. Mahr, "Numerisches Berechnen und tomographisches Messen zwei-phasiger Strömugsfelder in geordneten Schichtungen," in Institut für Verfahrenstechnik, Leibnitz Universität Hannover, Hanover, Germany, 2007.

[9] B. Mahr and D. Mewes, "X-ray tomographic visualization of liquid spreading in structured packings using contrast-agent tracer," in Proceedings of the 13th International Heat Transfer Conference (IHTC '06), Sydney, Australia, 2006.

[10] J. U. Repke, I. Ausner, S. Paschke, A. Hoffmann, and G. Wozny, "On the track to understanding three phases in one tower," Chemical Engineering Research and Design, vol. 85, no. 1, pp. 50-58, 2007.

[11] A. Hoffmann, I. Ausner, J. U. Repke, and G. Wozny, "Fluid dynamics in multiphase distillation processes in packed towers," Computers and Chemical Engineering, vol. 29, no. 6, pp. 1433-1437, 2005.

[12] A. Hoffmann, I. Ausner, J. U. Repke, and G. Wozny, “Detailed investigation of multiphase (gas-liquid and gas-liquid-liquid) flow behaviour on inclined plates," Chemical Engineering Research and Design, vol. 84, no. 2, pp. 147-154, 2006.

[13] Y. Xu, S. Paschke, J. U. Repke, J. Yuan, and G. Wozny, "Portraying the countercurrent flow on packings by three-dimensional computational fluid dynamics simulations," Chemical Engineering and Technology, vol. 31, no. 10, pp. 1445-1452, 2008.

[14] Y. Haroun, D. Legendre, and L. Raynal, "Direct numerical simulation of reactive absorption in gas-liquid flow on structured packing using interface capturing method," Chemical Engineering Science, vol. 65, no. 1, pp. 351-356, 2010.

[15] Y. Haroun, D. Legendre, and L. Raynal, "Volume of fluid method for interfacial reactive mass transfer: application to stable liquid film," Chemical Engineering Science, vol. 65, no. 10, pp. 2896-2909, 2010.

[16] J. M. van Baten and R. Krishna, "Gas and liquid phase mass transfer within KATAPAK-S structures studied using CFD simulations," Chemical Engineering Science, vol. 57, no. 9, pp. 1531-1536, 2002.

[17] A. Viva, S. Aferka, D. Toye, P. Marchot, M. Crine, and E. Brunazzi, "Determination of liquid hold-up and flow distribution inside modular catalytic structured packings," Chemical Engineering Research and Design, vol. 89, no. 8, pp. 1414-1426, 2011.

[18] Ansys Fluent 12.0 User Guide, 2009.

[19] J. U. Brackbill, "A continuum method for modeling surface tension," Journal of Computational Physics, vol. 100, no. 2, pp. 335-354, 1992.

[20] K. Subramanian, S. Paschke, J. U. Repke, and G. Wozny, "Drag force modelling in CFD simulation to gain insight of packed columns," in Proceedings of the 9th International Conference on Chemical and Process Engineering, (ICheaP '09), pp. 561-566, May 2009.

[21] Ansys ICEM CFD Manual 12.1, 2009.
[22] S. Paschke, Experimentelle Analyse ein- und zweiphasiger Filmströmungen aufglatten und strukturierten Oberflächen, TU Berlin, Berlin, Germany, 2011.

[23] A. Viva, S. Aferka, E. Brunazzi, P. Marchot, M. Crine, and D. Toye, "Processing of X-ray tomographic images: a procedure adapted for the analysis of phase distribution in MellapakPlus 752.Y and Katapak-SP packings," Flow Measurement and Instrumentation, vol. 22, no. 4, pp. 279-290, 2011. 

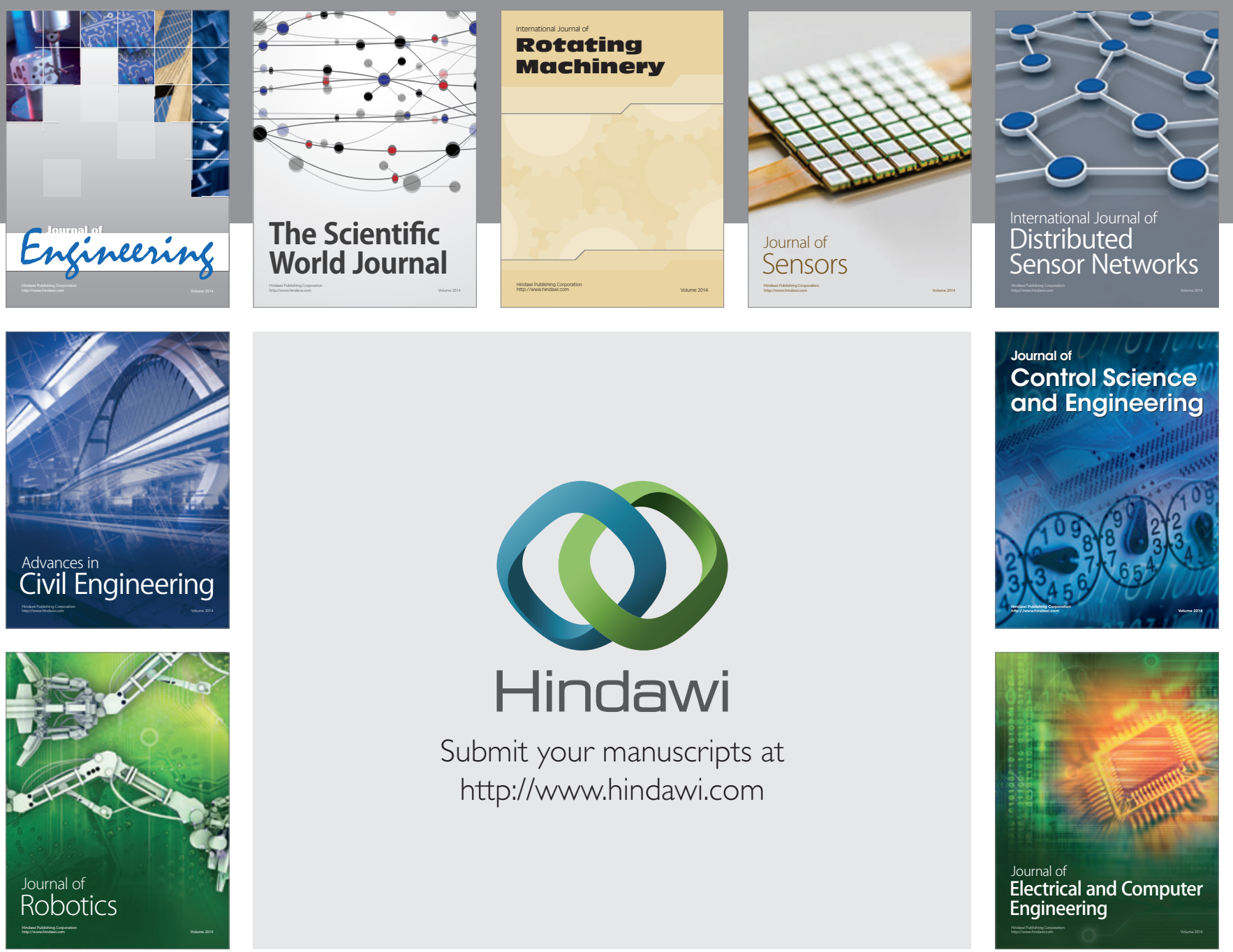

Submit your manuscripts at

http://www.hindawi.com
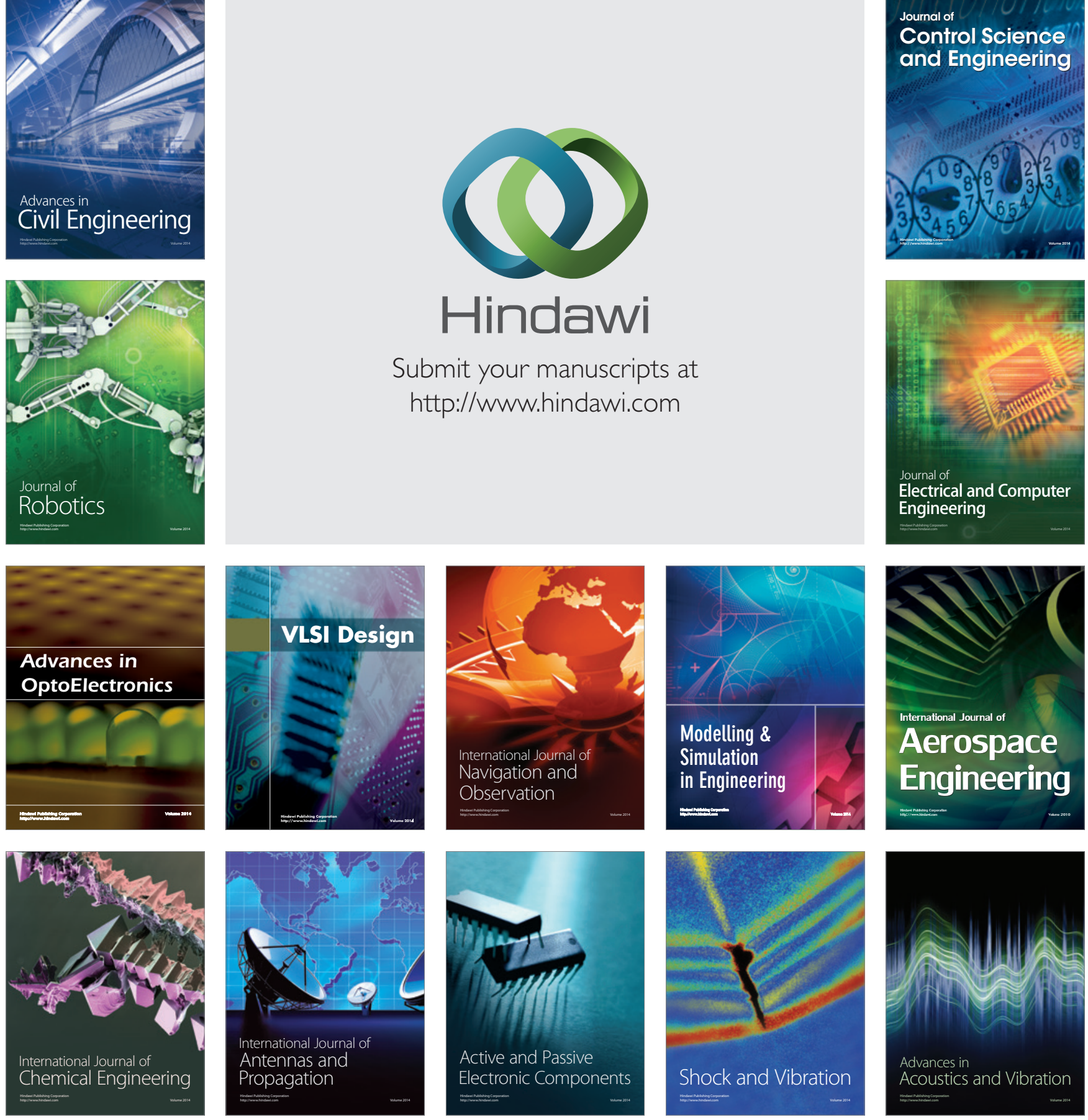